\title{
Characterization of Rolled and Recrystallized High-Purity Nickel Using EBSP
}

\author{
H. Chang and I. Baker
}

Thayer School of Engineering, Dartmouth College, 8000 Cummings Hall, Hanover, NH 03755

As-received, cold rolled and isothermally-recrystallized textures of high purity nickel were studied using electron back-scattered diffraction patterns (EBSP) in a scanning electron microscope (SEM). The evolution of the recrystallization texture was investigated as a function of annealing temperature.

99.995\% purity polycrystalline nickel, purchased received from Alfa Aesar, was rolled to either $90 \%, 95 \%$ or $98 \%$ thickness reduction at either $293 \mathrm{~K}$ or $77 \mathrm{~K}$. The rolled specimens were isothermally annealed in air at their primary recrystallization temperatures and higher temperatures up to $1273 \mathrm{~K}$ for $1 \mathrm{~h}$. For SEM/EBSP examination, specimens were mechanically polished, followed by electro-polishing in $10 \%$ sulfuric acid in methanol, at a voltage of $\sim 14 \mathrm{~V}$, a current density of $\sim 65 \mathrm{~mA} / \mathrm{cm}^{2}$ and a temperature $<273 \mathrm{~K}$.

SEM/EBSP study of the as-received nickel showed a strong fiber texture with both $<111>/ / \mathrm{RD}$ and $<100>/ / \mathrm{RD}$, which is characteristic of extrusion. All the subsequently rolled specimens showed textures typical of a rolled low stacking fault energy f.c.c. metal, see figure 1. A texture composed of both cube and remnant rolling components was observed in the nickel that was $90 \%$ cold rolled at $293 \mathrm{~K}$ followed by primarily recrystallization at $673 \mathrm{~K}$ for $1 \mathrm{~h}$, while a sharp cube texture was observed in nickel $98 \%$ cold rolled at $293 \mathrm{~K}$ and primarily recrystallized at $658 \mathrm{~K}$ for $1 \mathrm{~h}$, see figure 2. In other words, increasing the rolling reduction sharpened the primary-recrystallized, cube texture. Figure 3 shows the $\{100\}$ pole figures of nickel rolled to $98 \%$ thickness reduction at $77 \mathrm{~K}$ or $293 \mathrm{~K}$, followed by primary recrystallization at $643 \mathrm{~K}$ and $673 \mathrm{~K}$, respectively. It can be seen that decreasing the rolling temperature does not sharpen the primary-recrystallized cube texture. Abnormal grain growth was found after annealing the rolled specimens at $873 \mathrm{~K}$ for $1 \mathrm{~h}$. Therefore, in order to observe the texture evolution after secondary recrystallization, the rolled specimens were annealed at $1273 \mathrm{~K}$ for 1 hour. As shown by the pole figure in figure 4 , a strong $\{124\}<211>$ texture was observed, which was also found in our prior study [1] as the preferred orientation for secondary recrystallization in cold rolled nickel. The orientation map in figure 4 shows that the $\{124\}<211>$ oriented grains comprise about $73 \%$ of the total investigated area and, a very small fraction of cube oriented grains still exist in the microstructure.

In conclusion, increasing the thickness reduction during rolling sharpens the primarily recrystallized cube texture in high purity nickel while decreasing the rolling temperature does not. $\{124\}<211>$ was the preferred orientation for secondary recrystallization in nickel.

\section{References:}

[1] Baker I. and Li J., An EBSP study of Isothermally-annealed Cold-rolled Nickel. Microscopy Research and Technique, 63 (5): 289-297, 2004. 

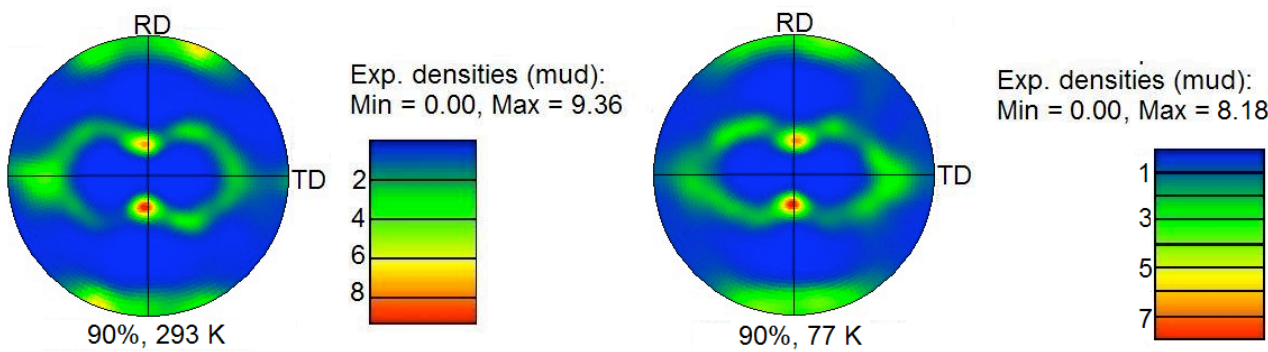

Figure 1. $\{111\}$ pole figures of nickel specimens $90 \%$ and $98 \%$ cold rolled at room temperature. The scale shows the probability of the orientation of a particular crystallographic axis.
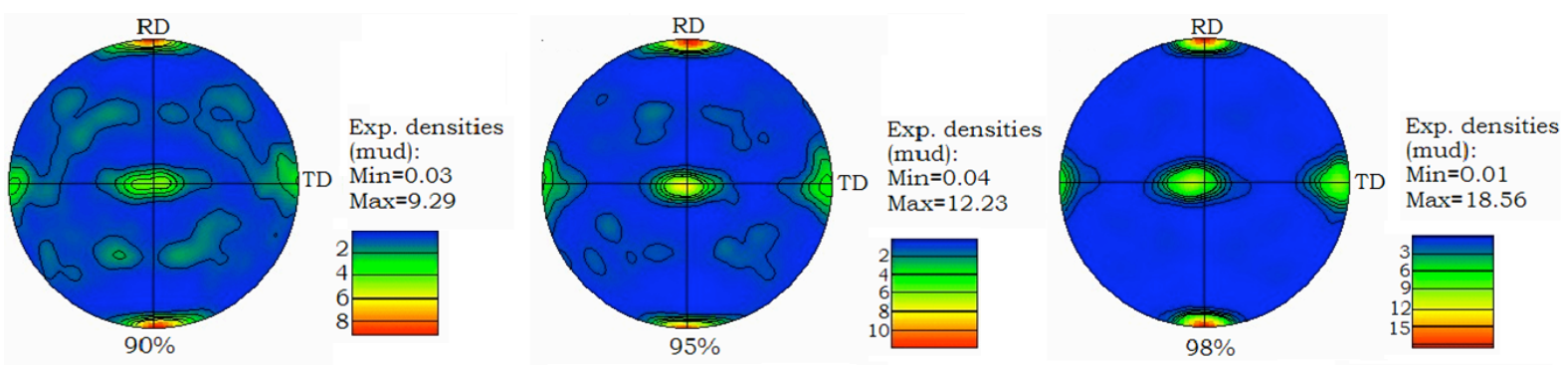

Figure 2. $\{100\}$ pole figures of nickel cold rolled to $90 \% 95 \%$ and $98 \%$ reductions at $293 \mathrm{~K}$, annealed at $673 \mathrm{~K}, 663 \mathrm{~K}$ and $658 \mathrm{~K}$ for $1 \mathrm{~h}$, respectively. The scale shows the probability of the orientation of a particular crystallographic axis.
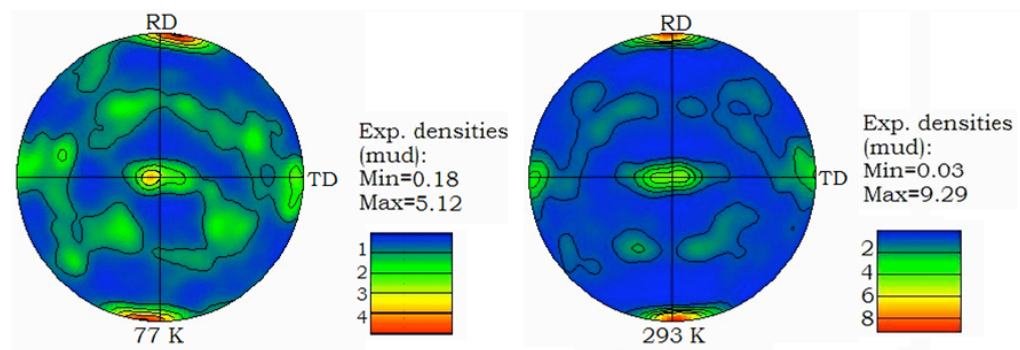

Figure 3. $\{100\}$ pole figures of nickel $90 \%$ rolled at $77 \mathrm{~K}$ and $293 \mathrm{~K}$, annealed at $643 \mathrm{~K}$ and $673 \mathrm{~K}$, respectively. The scale shows the probability of the orientation of a particular crystallographic axis.
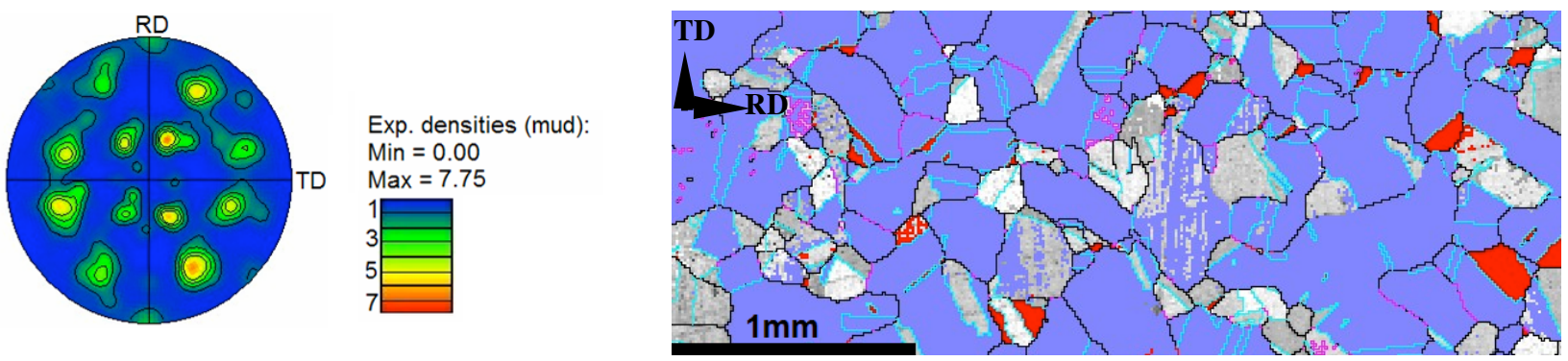

Figure 4. $\{100\}$ pole figure of nickel $98 \%$ cold rolled at $293 \mathrm{~K}$, annealed at $1273 \mathrm{~K}$ for $1 \mathrm{~h}$. The scale shows the probability of the orientation of a particular crystallographic axis, and an orientation map from the same specimen, $\{124\}<211>$ grains are blue, cube grains are red, $\Sigma 3$ boundaries are aqua. Grain boundaries and orientations are set on a $10^{\circ}$ misorientation angle. 